\title{
Canadian National Dairy Study: Heifer calf management
}

\author{
Charlotte B. Winder, ${ }^{* 1}$ Cathy A. Bauman, ${ }^{*}$ Todd F. Duffield, ${ }^{*}$ Herman W. Barkema, $†$ Greg P. Keefe,‡ \\ Jocelyn Dubuc,§ Fabienne Uehlinger,\# and David F. Kelton* \\ *Department of Population Medicine, University of Guelph, Ontario, Canada N1G 2W1 \\ †Department of Production Animal Health, University of Calgary, Alberta, Canada T2N 1N4 \\ fDepartment of Health Management, University of Prince Edward Island, Canada C1A 4P3 \\ §Faculté de Médecine Vétérinaire, Université de Montréal, Québec, Canada J2S 2M2 \\ \#Department of Large Animal Clinical Sciences, University of Saskatchewan, Saskatchewan, Canada S7N 5B4
}

\section{ABSTRACT}

In the past decade, substantial changes have occurred in the way dairy heifer calves are managed. The objectives of this study, part of phase I of the 2015 Canadian National Dairy Study, were to examine heifer calf health and adoption of rearing practices, and to explore factors associated with different rearing strategies on Canadian dairy farms. The questionnaire was open to all licensed dairy producers in Canada and had a $12 \%$ response rate $(\mathrm{n}=1,373)$. Fifty-one percent of respondents reported never allowing heifer calves to nurse their dam, and $17 \%$ always removed calves within 30 min of birth. Sixty-seven percent reported always feeding heifer calves $4 \mathrm{~L}$ of colostrum within $12 \mathrm{~h}$ of birth; $17 \%$ always fed colostrum between 2100 and $0400 \mathrm{~h} ; 5 \%$ pasteurized all colostrum fed on farm. Seventy-seven percent of respondents reported calving and stillbirth information for 2014; the mean reported stillbirth rate was $4.9 \%(\mathrm{SD}=3.3)$. Forty percent housed calves in individual pens, $34 \%$ in group pens, $21 \%$ in individual hutches, $2 \%$ reported tethering calves, and $1 \%$ used group hutches. Of those who housed calves in groups, $59 \%$ reported a maximum group size of 3 to 10 calves, $31 \%$ reported a pair (2) of calves per pen or hutch, and $10 \%$ reported a group $>10$ calves. The maximum amount of milk offered to calves per day during the preweaned period was a mean of $8 \mathrm{~L}(\mathrm{SD}=3)$. Fifty percent of respondents reported mortality data for 2014; mean preweaning mortality was $6.4 \%(\mathrm{SD}=8.3)$, and postweaning mortality was $2.4 \%(\mathrm{SD}=4.4)$. Over $95 \%$ of producers reported disbudding practices; $86 \%$ used cautery, $11 \%$ used surgical amputation, and $9 \%$ used caustic paste. Twenty-eight percent reported disbudding at less than $3 \mathrm{wk}$ of age, $60 \%$ at 3 to $8 \mathrm{wk}$, and $22 \%$ at 8 to 16 wk; $5 \%$ of respondents reported dehorning

\footnotetext{
Received March 2, 2018

Accepted July 9, 2018.

${ }^{1}$ Corresponding author: winderc@uoguelph.ca
}

at more than 16 wk of age. Sixty-six percent of cautery users reported use of local anesthetic, $33 \%$ used sedation, and $25 \%$ used a nonsteroidal anti-inflammatory drug (NSAID). Multivariable regression models showed that the use of local anesthetic when disbudding calves was associated with social media activity (odds ratio $=2.3$ ) and high-speed internet access (odds ratio $=$ 2.0), whereas sedation was associated with geographic region, and NSAID use was associated with disbudding at more than 3 wk of age. Exploring heifer rearing management practices, including adoption of best practices, may help focus future education and extension efforts. Poor reporting of mortality data may reflect a lack of recordkeeping on farm.

Key words: calf management, housing, disbudding, mortality

\section{INTRODUCTION}

Care and management of dairy heifer calves early in life has substantial short- and long-term effects, from affecting calf morbidity and mortality rates (TrotzWilliams et al., 2008; Raboisson et al., 2013) to firstlactation milk production (Soberon and Van Amburgh, 2013; Gelsinger et al., 2015). In the past decade, the way dairy heifer calves are managed has changed substantially, with changes in diet composition, total calories fed, housing, and feeding strategies. Additionally, new research into the impact of maternal and epigenetic effects has shown that maternal nutrition and management can affect calf performance (Kertz et al., 2017). Animal welfare standards have also changed globally (von Keyserlingk and Weary, 2017), with use of pain control for dehorning as part of the mandatory proAction Animal Care program for dairy farmers in Canada (Dairy Farmers of Canada, 2015). Although some evidence suggests that the use of pain control has increased in the province of Ontario in recent years (Winder et al., 2016), no national data have been collected regarding this practice. 
The first Canadian National Dairy Study was designed based on identified management and disease priorities of Canadian dairy industry stakeholders (Bauman et al., 2016), and collected data from farms in all provinces regardless of enrollment in milk recording (Belage et al., 2017). This information has facilitated benchmarking of management practices, similar to the National Animal Health Monitoring System (NAHMS) in the United States (USDA-APHIS, 2016). Although there has been a national survey of milk feeding practices (Medrano-Galarza et al., 2017), other early life management practices, as well as morbidity and mortality rates, have not been described at the Canadian national level. Benchmarking calf performance has been shown to improve farmer confidence in assessment of their own management, and is able to shift social norms regarding these practices (Sumner et al., 2018).

The objectives of this study were to quantify heifer calf management practices in early life, including the use of pain control for disbudding, and to document pre- and postweaning heifer mortality rates on Canadian dairy farms. Factors associated with early life management practices and stillbirth and mortality events were explored using multivariable regression models.

\section{MATERIALS AND METHODS}

\section{Survey Design and Administration}

The first National Canadian Dairy Study was conducted in 2015 as a multi-institutional study with collaboration between the universities of Calgary, Guelph, Montreal, and Prince Edward Island. This study consisted of 2 phases, the first of which was a questionnaire offered to all Canadian dairy producers between March 1 and April 30, 2015. The focus of the questionnaire was derived from a priority assessment of Canadian dairy industry stakeholders conducted in 2014 (Bauman et al., 2016). Before implementation, the questionnaire was given to an advisory group specific to the project, consisting of dairy producers, industry representatives, and veterinarians, which included representation from all provinces (Bauman et al., 2018). The questionnaire was then amended to improve relevance, clarity, and ease of understanding (Bauman et al., 2018). Research ethics boards from all collaborating institutions approved the questionnaire (University of Calgary, REB\#14-2481, University of Guelph, REB\#14DC025, University of Montreal, 15-007-CERES-D, University of Prince Edward Island, REB\#6006095). The 189-question survey was offered in both English and French, and was available online with the Qualtrics platform (https: //www.qualtrics.com/) or as a hard copy or telephone survey, and invitations were sent to all licensed dairy producers in Canada by a third party. English telephone interviews were conducted by the second author (C. Bauman) and those in French were conducted by a master's student involved with the study (E. Belage). Reminders to complete the survey were posted on organizational websites and social media such as Facebook and Twitter. Bauman et al. (2016) provides further information about the survey design and administration. The full questionnaire is available online at http://www .nationaldairystudy.ca/s/NDS-Survey-English.pdf.

\section{Statistical Analyses}

Data Cleaning. Data were first entered into a Qualtrics survey, and then exported into Excel (Microsoft, Redmond, WA), and from there into Stata/IC 13.1 (StataCorp, College Station, TX) for cleaning and analysis. Respondents milking $\leq 10$ cows or those not reporting their lactating herd size were excluded from further analysis $(\mathrm{n}=76)$. Respondents did not have to complete all sections of the phase I survey to have their answers offered for analysis. Variables examined in this study included farm and individual demographics (9 questions); biosecurity practices pertaining to calving management and newborn calves (4 questions), and 1 question on participation in a Johne's disease control program; all questions on heifer calf health (9 questions); 1 question on knowledge of the Code of Practice (National Farm Animal Care Council, 2009); all questions on disbudding or dehorning (13 questions); questions pertaining to pre- and postweaning heifer calf mortality (4 questions); questions on use of social media (6 questions); dial-up internet connection (1 question); and 1 question on willingness to do a follow-up during the farm visit phase of the survey (phase II of the National Dairy Study). Stillbirth information was captured in the demographic section, and participants were asked to report the number of calves born dead or died within the first $48 \mathrm{~h}$ between January 1 and December 31, 2014.

Binary outcomes containing $<5 \%$ response in one category were excluded from analysis; categorical outcomes with $<5 \%$ variation were collapsed into fewer broader categories. Ordinal variables regarding newborn calf management practices and biosecurity practices were reported descriptively but collapsed into binary outcomes for further analysis.

Mortality data for pre- and postweaning heifers had the lowest response rate of all questions analyzed in this manuscript; $29 \%$ of respondents did not offer an answer for any questions in this section $(\mathrm{n}=314)$. Of those who did respond to this section $(\mathrm{n}=762), 33 \%(\mathrm{n}=$ 251) reported having had zero preweaning heifer deaths and euthanasia in 2014. This was assumed unlikely; 
even though some farms, particularly smaller ones, may indeed have had zero heifer mortality in 2014, it was unlikely this was true for all $33 \%$ of respondents. To remove those most likely to have given an incorrect response, all respondents who reported a zero for all heifer mortality categories, both pre- and postweaning, were discarded for these analyses $(\mathrm{n}=182)$. If a zero value was reported for either preweaned or postweaning (but not both), such that the other had a nonzero value, respondents were included and the zero value was kept. This left 578 respondents with usable data for the preweaned heifer mortality ( $54 \%$ of total respondents), and 580 respondents for postweaning heifer mortality, as some participants gave information for one section but not the other. Median farm size was examined and did not differ between the included (54 milking cows) and excluded (55 milking cows) respondents.

Model Building. Predictive models were built to examine factors associated with 4 newborn calf management practice questions in the Calf Health section of the survey. Those who reported always removing heifer calves within $30 \mathrm{~min}$ of birth were a complete subset of those who reported never allowing heifer calves to nurse their dams; this question was not described further. Pasteurized colostrum was only fed on a small number of farms and was not examined further. After examining the descriptive statistics for these questions, the questions were collapsed into those answering "always" and those answering anything else ("most of the time," "occasionally," and "never") for "regarding newborn heifer calves, how often do you" - "remove them within 30 min of birth?"; "ensure they receive at least $4 \mathrm{~L}$ of good quality colostrum within the first $12 \mathrm{~h}$ ?"; and "feed colostrum between 2100 and $0500 \mathrm{~h}$ ?" The question with the predicate "allow them to nurse their dam" was collapsed into "never" and those answering anything else ("always," "most of the time," "occasionally"). These binary outcomes were then explored using logistic regression models. Maximum volume of milk fed to preweaned calves was explored using linear regression. Stillbirth and preweaned mortality percentage were categorized into those producers with below- and above-average values from this study and explored using logistic regression.

Questions examined as described under "data cleaning" were offered as possible dependent variables to the models and are detailed in Table 1. Disbudding/dehorning questions were collapsed into 4 variables regarding age at disbudding/dehorning, and 3 on method; preand postweaning mortality were offered as 2 variables; and social media use questions were collapsed into producers who used social media (as a source of information for the farm) as a binary outcome. All variables were checked against each other for possible collinearity if Spearman's rank correlation was $\geq 0.70$; no collinear variables were found in our analysis.

Final models were built in 2 steps. First, univariate associations were examined, and those variables with $P$ $<0.20$ were offered to the multivariate model. Manual forward selection was used with a cut-point of $P<0.05$. Nonsignificant variables were checked for confounding before removal; that is, if their removal changed the coefficients of the remaining variables by $>20 \%$. Final models were checked for potential interaction terms between those determined a priori to be potentially important; if geographic region remained in the final model, interaction terms between this and all management practices were examined, and kept in the model if $P<0.05$. Logistic regression models with binomial data were assessed for fit using Pearson's chi-squared and deviance goodness of fit, with the null hypothesis that the model fits the data, and visual examination of Pearson and deviance residuals. The assumption of linearity of continuous predictor variables was assessed graphically using locally weighted scatterplot smoothing of the log odds of the outcome. Residuals from models with binary data were visually examined to identify potential influential covariate patterns. Linear regression models were examined for homoscedasticity using the Cook-Weisberg test, and normality using the Shapiro-Wilk test, with the null values indicating the model fit the data.

\section{RESULTS}

\section{Response Rate}

Based on the number of active dairy producers identified by the provincial milk marketing boards as of February 2015, the 1,373 respondents to the survey reflected $12 \%$ of the Canadian national dairy herd. Of these, $119(9 \%)$ responses were completed by paper copy and $52(4 \%)$ were completed over the phone. A total of 297 respondents were removed from further analysis because they either reported milking $\leq 10$ cows or did not provide information on the number of milking cows. Therefore, 1,076 (78\%) respondents were considered for our analysis, although not all respondents answered all survey questions. Level of responses throughout the survey sections considered are outlined in Figure 1.

\section{Demographics}

Farm Demographics. The majority of respondents were from Québec (43\%) and Ontario (37\%), with $13.5 \%$ from Western provinces [Alberta (5\%), British Columbia (4\%), Manitoba (3.5\%), and Saskatchewan (1\%)] and 6.5\% from Atlantic provinces [New Brunswick 
Table 1. Variables offered on univariable analysis for all predictive model building ${ }^{1}$

\begin{tabular}{|c|c|c|}
\hline Area & Variable & Type \\
\hline Biosecurity & $\begin{array}{l}\text { Never house sick or lame cows in the calving pen } \\
\text { Always clean calving pen between cows } \\
\text { Always clean legs and udder before calving } \\
\text { Participated in a Johne's control program in the past } 5 \mathrm{yr}\end{array}$ & $\begin{array}{l}\text { Binary } \\
\text { Binary } \\
\text { Binary } \\
\text { Binary }\end{array}$ \\
\hline Code of Practice ${ }^{2}$ & Consulted in the past $2 \mathrm{mo}$ & Binary \\
\hline Disbudding & $\begin{array}{l}\text { Disbud }<3 \text { wk of age } \\
\text { Caustic paste } \\
\text { Cautery } \\
\text { Use of local anesthetic } \\
\text { Use of sedation } \\
\text { Use of nonsteroidal anti-inflammatory drug }\end{array}$ & $\begin{array}{l}\text { Binary } \\
\text { Binary } \\
\text { Binary } \\
\text { Binary } \\
\text { Binary } \\
\text { Binary }\end{array}$ \\
\hline Mortality & $\begin{array}{l}\text { Stillbirth }(\%) \\
\text { Preweaning calf mortality }(\%) \\
\text { Postweaning calf mortality }(\%)\end{array}$ & $\begin{array}{l}\text { Continuous } \\
\text { Continuous } \\
\text { Continuous }\end{array}$ \\
\hline
\end{tabular}

${ }^{1}$ Variables with $P<0.20$ on univariable analysis were offered to the multivariable model through manual forward selection.

${ }^{2}$ Code of Practice for the Care and Handling of Dairy Cattle (National Farm Animal Care Council, 2009).

$(2 \%)$, Newfoundland and Labrador $(0.5 \%)$, Nova Scotia $(2 \%)$, and Prince Edward Island $(2 \%)]$. This is similar to the regional distribution of dairy farms in that year (Québec 49\%, Ontario 33\%, Western provinces 12\%, Atlantic provinces 6\%; Canadian Dairy Commission, 2015). Three percent of respondents were certified to produce organic milk, and $86 \%$ were enrolled in milk recording. Sixty percent of respondents had a tiestall barn, $37 \%$ a freestall barn, and $3 \%$ a bedded pack barn to house the lactating herd. Sixty percent of respondents had a pipeline milking system, $29 \%$ milked in a parlor, and $11 \%$ used an automated milking system. Mean number of milking cows was $77(\mathrm{SD}=80$, range $=12$ to 1,037 ).

Producer Demographics. The majority (87\%) of respondents were the farm owner, with the remainder being staff or family members. Thirty-six percent of respondents were $\geq 50 \mathrm{yr}$ of age, $24 \%$ were aged 40 to 49 yr, $26 \%$ aged 30 to $39 \mathrm{yr}$, and $14 \%$ were $\leq 30 \mathrm{yr}$ of age.
Thirty-five percent reported their level of education as completed high school or less, $47 \%$ reported having a college diploma, and $18 \%$ reported having a college, university, or (and) a postgraduate degree.

\section{Calf Health and Management Practices}

Colostrum Feeding and Newborn Calf Management. Regarding newborn heifer calves on the dairy farm, respondents were asked to state how commonly several practices occurred, with options of "always," "most of the time," "occasionally," or "never" (Table 2). Half $(51 \%)$ of respondents reported calves were never allowed to nurse their dam; however, only $17 \%$ always removed calves within 30 min of birth. A total of $67 \%$ reported that they always fed $4 \mathrm{~L}$ of good-quality colostrum within the first $12 \mathrm{~h}$ of life. Although the majority $(74 \%)$ of those who stated they never allowed calves to nurse their dams also reported always feeding 


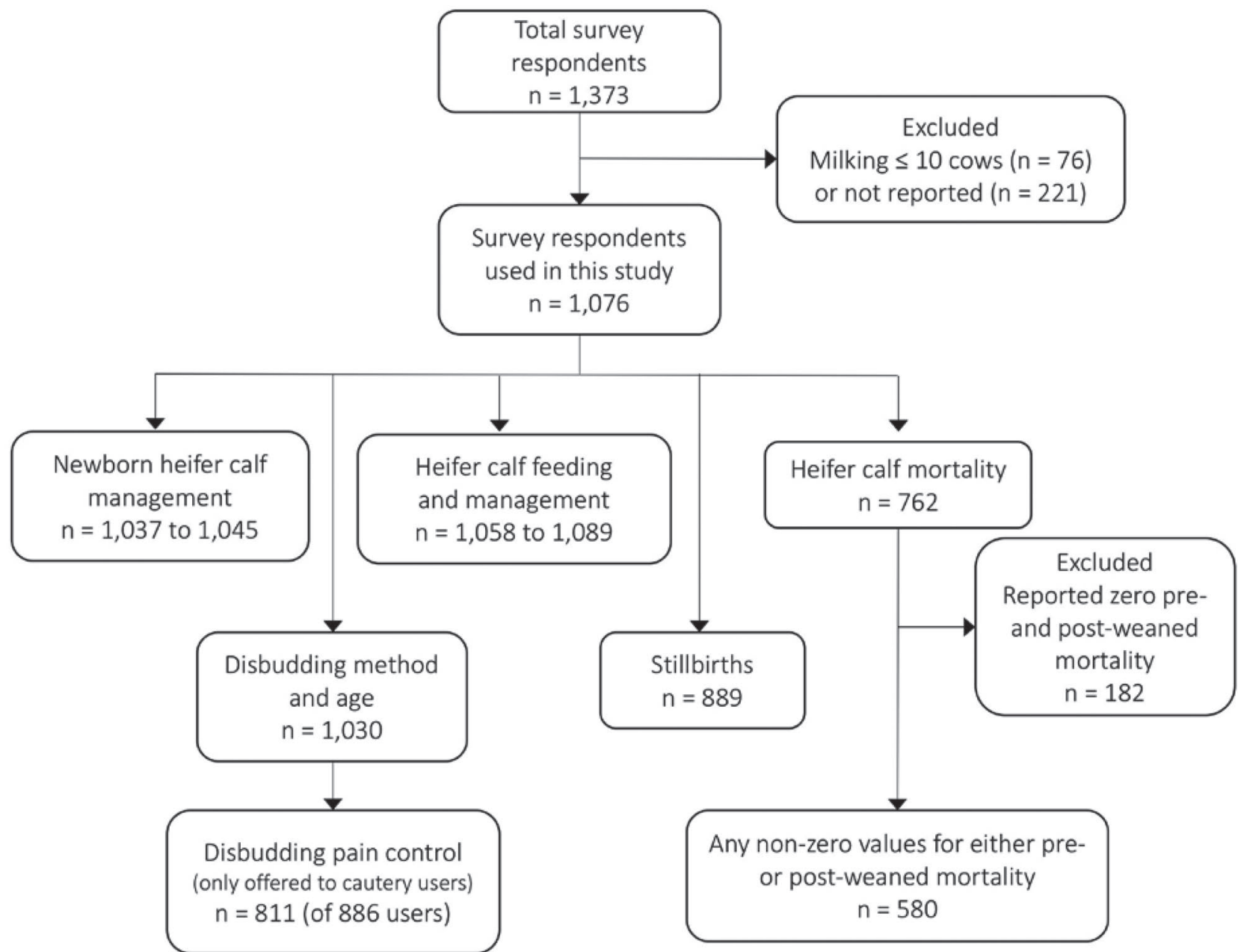

Figure 1. Flowchart showing number of responses to individual survey sections. Because of a technical error, questions on disbudding pain control were only offered to those selecting cautery as their disbudding method.

colostrum, some reported both never allowing nursing, and not always feeding these calves within the first $12 \mathrm{~h}$ (Figure 2). Feeding colostrum between 2100 and $0500 \mathrm{~h}$ was uncommon, with $41 \%$ reporting occasional overnight feedings, and $23 \%$ never feeding during this time (Table 2). Feeding heat-treated colostrum at least some of the time was reported by $12 \%$ of respondents (Table 2).
Factors Associated with Colostrum Feeding and Newborn Calf Management. Never allowing calves to nurse their dams was associated with region and age of respondent, with respondents from Québec being more likely to report this practice, and respondents $<30 \mathrm{yr}$ of age having 1.7 times the odds of reporting this practice than those $\geq 50$ yr of age (Table 3 ). Concern for cleanliness of the cow and pen, including

Table 2. Summary of responses to questions regarding newborn heifer calf management practices on 1,076 Canadian dairy farms

\begin{tabular}{|c|c|c|c|c|c|}
\hline $\begin{array}{l}\text { Regarding newborn heifer calves on your farm, } \\
\text { how often do you }\end{array}$ & $\mathrm{n}$ & $\begin{array}{l}\text { Always } \\
{[\% \text { (no.) }]}\end{array}$ & $\begin{array}{l}\text { Most of the time } \\
{[\% \text { (no.) }]}\end{array}$ & $\begin{array}{l}\text { Occasionally } \\
{[\%(\text { no. })]}\end{array}$ & $\begin{array}{l}\text { Never } \\
{[\%(\text { no. })]}\end{array}$ \\
\hline Allow them to nurse their dam? & 1,045 & $4(42)$ & $10(102)$ & $35(368)$ & $51(533)$ \\
\hline Remove them within 30 min of birth? & 1,043 & $17(182)$ & $34(351)$ & $26(275)$ & $23(235)$ \\
\hline Feed colostrum between 2100 and $0500 \mathrm{~h} ?$ & 1,037 & $17(173)$ & $20(206)$ & $41(426)$ & $23(232)$ \\
\hline Feed heat-treated colostrum? & 1,038 & $5(51)$ & $3(27)$ & $5(47)$ & $88(913)$ \\
\hline
\end{tabular}




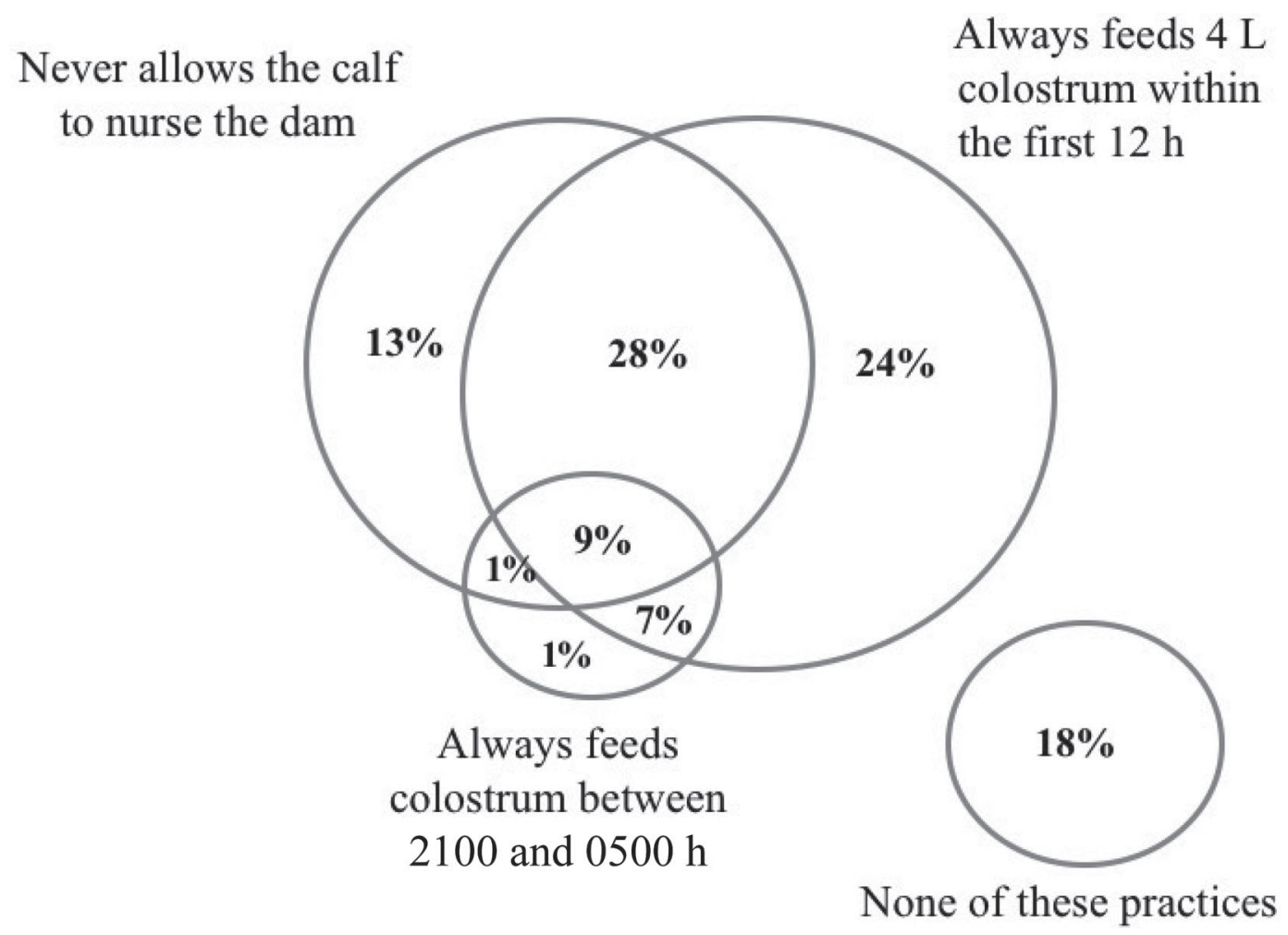

Figure 2. Overlap of the 1,036 Canadian dairy producer respondents who answered the following 3 questions: Regarding newborn heifer calves on your dairy farm, how often do you ... Allow the calf to nurse the dam? Feed at least $4 \mathrm{~L}$ of good-quality colostrum within the first $12 \mathrm{~h}$ ? Feed colostrum between 2100 and 0500 h? Options were "always," "most of the time," "occasionally," and "never." Overlap is presented between those who answered "never" to allowing calves to nurse their dam, and "always" to the second 2 questions.

use of a dedicated calving pen, were also associated with this practice, with respondents using a dedicated calving pen having 2.5 times the odds of reporting that they never allowed calves to nurse their dam (Table 3 ). Always removing calves within 30 min of birth was also associated with use of a dedicated calving pen [odds ratio $(\mathbf{O R})=2.4$ ], as well as feeding colostrum between 2100 and $0500 \mathrm{~h}(\mathrm{OR}=2.4)$, and increasing milk volume fed to preweaned calves $(\mathrm{OR}=1.1 \mathrm{per}$ $\mathrm{L} / \mathrm{d}$; Table 4). Always feeding heifer calves $4 \mathrm{~L}$ of goodquality colostrum within $12 \mathrm{~h}$ of birth was associated with other colostrum feeding practices, such as always feeding colostrum between 2100 and $0500 \mathrm{~h}(\mathrm{OR}=$ 6.2 , and was also associated with being aware of the Code of Practice for the Care and Handling of Dairy Cattle (NAFCC, 2009; Table 5). Similarly, always feeding colostrum between 2100 and $0500 \mathrm{~h}$ was associated with other newborn calf management practices but was less common for producers housing preweaned calves in groups $(\mathrm{OR}=0.7$; Table 6$)$.

Preweaning Calf Housing. Most preweaning heifer calves were reared in individual housing (63\% of producers). Forty percent housed calves in individual pens, $34 \%$ in group pens, $21 \%$ in individual hutches, $1 \%$ in group hutches, and $2 \%$ reported tethering calves. Tethering calves was not an option; respondents in this group selected "other" and wrote in this response and did not select "individual housing." It is possible some of the respondents reporting individual housing also tethered calves but did not report this. Of those who housed calves in groups, 31\% reported this group was typically a pair (2) of calves per pen or hutch, $59 \%$ reported maximum group sizes of 3 to 10 calves, and $10 \%$ had maximum group sizes $>10$ calves.

Preweaning Calf Feeding. A free-text response question asked for the maximum volume of milk or milk replacer fed to calve per day in the preweaning period; respondents reported a mean of $8.2 \mathrm{~L}$ as a maximum milk or milk replacer fed per day (Figure 3 ). A total of $33 \%$ of respondents fed a maximum of $\leq 6 \mathrm{~L} / \mathrm{d}$. There was an effect of age, with younger producers $(<30 \mathrm{yr}$ of age) feeding 0.7 to $0.8 \mathrm{~L}$ more than those 30 to 39 and 40 to $49 \mathrm{yr}$ of age, respectively (Table 7 ). Producers using group housing fed $1.2 \mathrm{~L}$ more milk per day than those with individual housing, whereas disbudding any calves at 8 to 16 wk of age was associated with 0.6 
Table 3. Final logistic regression model for factors associated with Canadian dairy producers reporting that they never allow newborn heifer calves to nurse their dams $(\mathrm{n}=937)$

\begin{tabular}{|c|c|c|c|c|}
\hline \multirow[b]{2}{*}{ Factor } & \multirow[b]{2}{*}{ Odds ratio } & \multicolumn{2}{|c|}{$95 \% \mathrm{CI}$} & \multirow[b]{2}{*}{$P$-value } \\
\hline & & Lower & Upper & \\
\hline \multicolumn{5}{|l|}{ Region (Québec referent) } \\
\hline Atlantic Canada ${ }^{1}$ & 0.5 & 0.3 & 0.8 & 0.01 \\
\hline Ontario & 0.4 & 0.3 & 0.5 & $<0.01$ \\
\hline Western Canada $^{2}$ & 0.2 & 0.1 & 0.4 & $<0.01$ \\
\hline Age of respondents ( $<30 \mathrm{yr}$ referent) & & 0.04 & 0.3 & $<0.01$ \\
\hline$\geq 50 \mathrm{yr}$ & 0.6 & 0.4 & 0.9 & 0.02 \\
\hline $30 \overline{M^{3}} E^{3}($ per $100 \mathrm{~kg})$ & 1.02 & 1.01 & 1.03 & $<0.01$ \\
\hline Never house sick or lame cows in the calving pen(s) & 2.5 & 1.8 & 3.5 & $<0.01$ \\
\hline Always clean the calving pen after use & 1.6 & 1.1 & 2.3 & 0.01 \\
\hline Always clean cow's legs and udder before calving & 1.5 & 1.1 & 2.0 & 0.02 \\
\hline Always feed $4 \mathrm{~L}$ of good-quality colostrum to heifer calves within the first $12 \mathrm{~h}$ & 1.4 & 1.0 & 1.9 & 0.03 \\
\hline Always feed heat-treated milk to newborn heifer calves & 2.6 & 1.3 & 5.3 & 0.01 \\
\hline
\end{tabular}

${ }^{1}$ Nova Scotia, New Brunswick, Prince Edward Island, and Newfoundland and Labrador.

${ }^{2}$ British Columbia, Alberta, Saskatchewan, and Manitoba.

${ }^{3} 305$-d mature-equivalent yield (predicted 305-d lactation performance adjusted for age and stage of lactation).

L less milk fed per day than those disbudding at a younger age (Table 7 ).

\section{Disbudding and Dehorning Practices}

Method and Age. Of producers answering questions on disbudding $(1,030), 28 \%$ reported disbudding at $<3 \mathrm{wk}$ of age, $60 \%$ reported disbudding at 3 to $8 \mathrm{wk}$ of age, $22 \%$ reported disbudding at 8 to 16 wk of age, and $5 \%$ reported dehorning at $>16 \mathrm{wk}$ of age. The most commonly used method was cautery, used by $86 \%$ of respondents, with $11 \%$ performing surgical amputation dehorning and $9 \%$ using caustic paste. Of those using cautery, $18 \%$ reported disbudding at $<3$ wk of age, $67 \%$ between 3 and 8 wk, $21 \%$ from 8 to 16 wk, and $1 \%$ at $>16$ wk of age. Seventy-three percent of caustic paste users disbudded at $<3$ wk of age, whereas $26 \%$ reported disbudding from 3 to 8 wk of age. Only 3 respondents reported disbudding with caustic paste after 8 wk of age. Whereas the majority of surgical amputation de- horning $(78 \%, \mathrm{n}=106)$ was performed at $\geq 8$ wk of age, 43 respondents (32\%) reported using amputation methods such as gouging for calves $<8$ wk of age. For all procedures, producers could select multiple categories, indicating that they performed procedure(s) to calves in several age ranges.

Use of Medications. Data about use of medication for anesthesia, analgesia, and sedation were only available for those who reported use of cautery disbudding, because of technical problems with the survey. A total of 811 respondents (92\% of cautery users) provided information on medication use. For those producers using cautery at $<3$ wk of age ( $18 \%$ of all cautery users), local anesthesia was used by $72 \%$, sedation by $33 \%$, and nonsteroidal anti-inflammatory drug (NSAID) analgesia by $30 \%$. For those using cautery at 3 to 8 wk of age ( $67 \%$ of cautery users), $68 \%$ reported use of local anesthetic, $34 \%$ used sedation, and $28 \%$ gave an NSAID. For those disbudding by cautery at 8 to 16 wk of age ( $21 \%$ of cautery users), $64 \%$ reported use of

Table 4. Final logistic regression model for factors associated with Canadian dairy producers reporting that they always remove heifer calves from the calving pen within 30 min of birth $(\mathrm{n}=964)$

\begin{tabular}{|c|c|c|c|c|}
\hline \multirow[b]{2}{*}{ Factor } & \multirow[b]{2}{*}{ Odds ratio } & \multicolumn{2}{|c|}{$95 \%$ CI } & \multirow[b]{2}{*}{$P$-value } \\
\hline & & Lower & Upper & \\
\hline Tiestall (vs. freestall or bedded pack) & 2.6 & 1.2 & 5.4 & 0.02 \\
\hline Never housing sick or lame cows in the calving pen & 2.4 & 1.5 & 3.9 & $<0.01$ \\
\hline Always cleaning the calving pen after use & 2.5 & 1.5 & 3.9 & $<0.01$ \\
\hline Always feeding colostrum between 2100 and $0500 \mathrm{~h}$ & 2.4 & 1.5 & 4.1 & 0.01 \\
\hline
\end{tabular}


Table 5. Final logistic regression model for factors associated with Canadian dairy producers reporting that they always feed heifer calves $4 \mathrm{~L}$ of good-quality colostrum within the first $12 \mathrm{~h}$ after birth $(\mathrm{n}=1,021)$

\begin{tabular}{|c|c|c|c|c|}
\hline \multirow[b]{2}{*}{ Factor } & \multirow[b]{2}{*}{ Odds ratio } & \multicolumn{2}{|c|}{$95 \% \mathrm{CI}$} & \multirow[b]{2}{*}{$P$-value } \\
\hline & & Lower & Upper & \\
\hline Always feeding colostrum between 2100 and $0500 \mathrm{~h}$ to heifer calves & 6.2 & 3.6 & 10.8 & $<0.01$ \\
\hline Always feeding heat-treated colostrum to heifer calves & 2.5 & 1.1 & 5.8 & 0.03 \\
\hline Aware of the Code of Practice ${ }^{1}$ & 1.4 & 1.0 & 2.0 & 0.04 \\
\hline Intercept & 0.9 & 0.7 & 1.5 & 0.76 \\
\hline
\end{tabular}

${ }^{1}$ Code of Practice for the Care and Handling of Dairy Cattle (National Farm Animal Care Council, 2009).

local anesthetic, $34 \%$ used sedation, and $21 \%$ gave an NSAID.

Predictors of Pain Control Use. For cautery disbudding users, the use of local anesthesia was positively associated with sedation: those using sedation had 21 times the odds of also using local anesthesia (Table 8). However, sedation was not a perfect predictor of local anesthesia; some producers who used this medication did not use local anesthesia. Use of technology was predictive of local anesthetic use; those reporting use of social media for farm purposes (e.g., to connect with other producers or to access and share information) had 2.5 times the odds of using local anesthesia compared with those who did not, whereas having a dial-up internet connection decreased the odds of reporting use of this medication $(\mathrm{OR}=0.5$; Table 8$)$. Use of sedation showed regional differences and was associated with use of an NSAID (OR $=2.0$; Table 8$)$. Use of NSAID analgesia was more likely $(\mathrm{OR}=1.8)$ in closed herds and far less likely $(\mathrm{OR}=0.1)$ if the farm disbudded any calves at less than 3 wk of age (Table 8).

\section{Stillbirths and Heifer Mortality}

Stillbirth data were available for 889 respondents (83\%), with a mean reported rate of $4.9 \%$ (Figure 4 ). Response rate for questions pertaining to heifer mortality was $71 \%$; 314 participants did not answer questions on heifer calf mortality. Of respondents to this section, $33 \%$ reported having had no preweaning heifer deaths or euthanasia in 2014. After removing those who also reported no deaths and euthanasia in weaned calves (182 respondents with zero values for all categories), 578 (54\% of respondents) remained with usable data on preweaning heifer mortality. Median farm size was examined and did not differ significantly between the included (54 milking cows, range $=13$ to 1,037 ) and excluded ( 55 milking cows, range $=12$ to 450 ) respondents. Mean mortality for these respondents in this period was $6.4 \%(\mathrm{SD}=8.3)$. Of all reported mortality events in the preweaning period, $89 \%$ were reported as deaths, whereas $11 \%$ were reported as euthanasia events. Of the 580 respondents with usable data regarding weaned heifer deaths (animals between weaning and first calving), mean mortality was $2.4 \%(\mathrm{SD}=4.4)$. Of all reported mortality events in this period, $76 \%$ were reported as deaths, whereas $24 \%$ were reported as euthanasia.

\section{Factors Associated with Calf Loss}

An increase in the number of milking cows was associated with reduced odds of having above-average preweaning calf mortality (per milking cow; $\mathrm{OR}=0.97$; 95\% CI: 0.97-0.98; $P<0.001$ ). For example, a herd milking 100 cows compared with 150 had 4.6 times the odds of having above-average preweaning calf mortality. This relationship appeared linear for farms milking up to 300 cows (98\% of respondents); for larger farms, the slope was essentially flat, showing no effect of this variable for this small subset ( $2 \%$ of respondents). Stillbirth percentage was associated with reported

Table 6. Final logistic regression model for factors associated with Canadian dairy producers reporting that they always feed newborn heifer calves colostrum between 2100 and $0500 \mathrm{~h}(\mathrm{n}=1,006)$

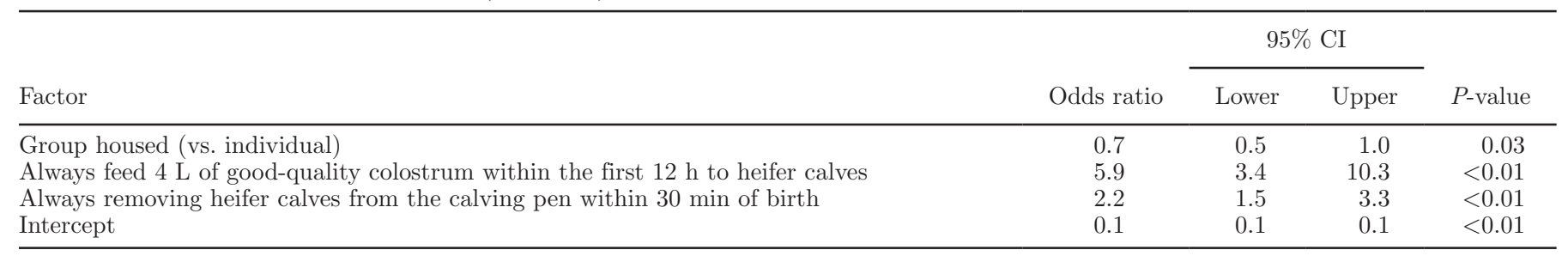




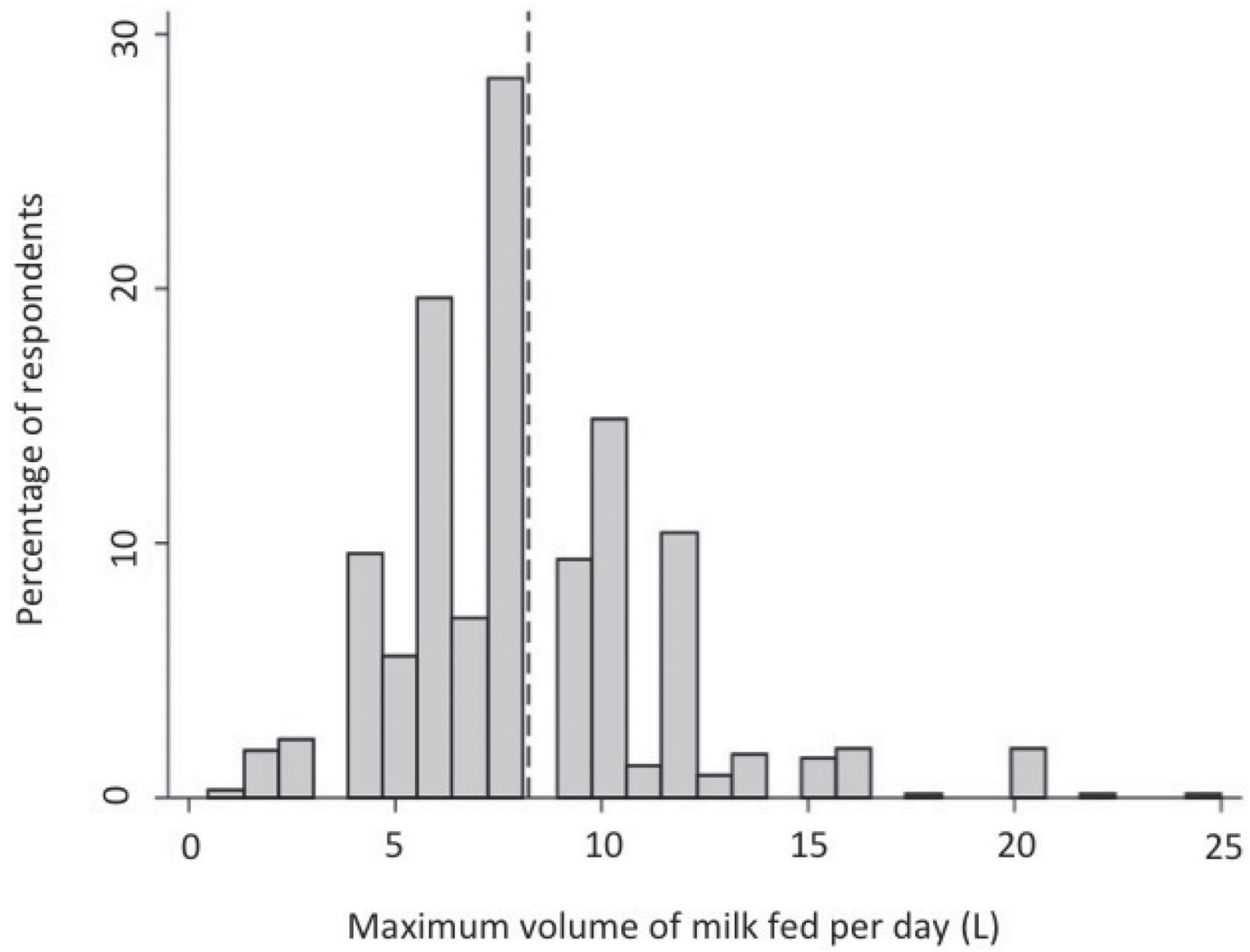

Figure 3. Distribution of maximum volume of milk or milk replacer fed per day to heifer calves by proportion of Canadian dairy producer respondents $(\mathrm{n}=989)$. The vertical dashed line reflects the mean value of $8.2 \mathrm{~L}$.

preweaning heifer mortality (per percentage point; OR $=1.1 ; 95 \%$ CI: $1.0-1.2 ; P=0.01)$, as was reported postweaning heifer calf mortality (per percentage point; $\mathrm{OR}=1.1 ; 95 \%$ CI: $1.1-1.2 ; P<0.001)$. For example, a herd with $5 \%$ higher postweaning calf mortality or $5 \%$ higher stillbirth rate had 1.6 times the odds of having above-average preweaned mortality. This relationship appeared to be linear. The final logistic regression model for factors associated with increased probability of above-average stillbirth rate $(\mathrm{n}=889)$ indicated a protective effect of the number of milking cows (per milking cow; $\mathrm{OR}=0.99 ; 95 \%$ CI: $0.99-0.99 ; P=0.01)$ and being a DHI participant $(\mathrm{OR}=0.3 ; 95 \%$ CI: $0.2-$ $0.5 ; P<0.001)$. For example, a herd milking 100 cows compared with 150 had 1.7 times the odds of having a stillbirth rate higher than average. This relationship appeared linear, although a steeper slope was present for farms milking $<40$ cows, indicating that the effect of this variable was more influential on these smaller farms ( $17 \%$ of respondents).

Table 7. Final linear regression model of factors associated with Canadian dairy producers reporting the maximum milk allowance (in L per day of milk or milk replacer) for preweaned heifer calves $(\mathrm{n}=813)$

\begin{tabular}{lrrrr}
\hline & & \multicolumn{2}{c}{$95 \%$ CI } & \\
Factor & $\beta^{1}$ & Lower & Upper & $P$-value \\
\hline Age of respondent (<30 yr referent) & & & & \\
30 to 39 yr & -0.7 & -1.5 & 0.1 & 0.08 \\
40 to 49 yr & -0.8 & -1.6 & -0.1 & 0.03 \\
$>50$ yr & -0.2 & -0.9 & 0.5 & 0.57 \\
Always clean the calving pen after use & 0.6 & 0.1 & 1.1 & 0.02 \\
Group housing (vs. individual) & 1.2 & 0.8 & 1.7 & $<0.01$ \\
Disbudding calves at 8 to 16 wk of age & -0.7 & -1.2 & -0.2 & 0.01 \\
Intercept & 8.2 & 7.6 & 8.9 & $<0.01$ \\
\hline
\end{tabular}

${ }^{1}$ Regression coefficient. 
Table 8. Final logistic regression model for factors associated with Canadian dairy producers reporting the use of local anesthetic, sedation, and nonsteroidal analgesia when performing cautery disbudding

\begin{tabular}{|c|c|c|c|c|}
\hline \multirow[b]{2}{*}{ Factor } & \multirow[b]{2}{*}{ Odds ratio } & \multicolumn{2}{|c|}{$95 \% \mathrm{CI}$} & \multirow[b]{2}{*}{$P$-value } \\
\hline & & Lower & Upper & \\
\hline \multicolumn{5}{|l|}{ Local anesthetic model $(\mathrm{n}=683)$} \\
\hline Use of social media & 2.3 & 1.4 & 3.8 & $<0.01$ \\
\hline Dial-up internet & 0.5 & 0.2 & 0.9 & 0.02 \\
\hline Use of sedation & 20.5 & 10.2 & 41.3 & $<0.01$ \\
\hline Intercept & 0.7 & 0.4 & 1.1 & 0.10 \\
\hline \multicolumn{5}{|l|}{ Sedation model $(\mathrm{n}=733)$} \\
\hline Use of local anesthetic & 23.6 & 12.2 & 45.7 & $<0.01$ \\
\hline Use of NSAID $^{1}$ & 2.0 & 1.4 & 3.0 & $<0.01$ \\
\hline \multicolumn{5}{|l|}{ Region (Québec referent) } \\
\hline Atlantic Canada $^{2}$ & 1.4 & 0.7 & 2.8 & 0.29 \\
\hline Ontario & 1.5 & 1.0 & 2.2 & 0.03 \\
\hline Western Canada $^{3}$ & 1.4 & 0.8 & 2.4 & 0.21 \\
\hline Intercept & 0.1 & 0.1 & 0.1 & $<0.01$ \\
\hline \multicolumn{5}{|l|}{ NSAID model $(\mathrm{n}=727)$} \\
\hline Closed herd & 1.8 & 1.3 & 2.6 & 0.01 \\
\hline Disbudding calves $<3$ wk of age & 0.1 & 0.04 & 0.3 & $<0.01$ \\
\hline Use of sedation & 1.5 & 1.0 & 2.1 & 0.04 \\
\hline Intercept (coefficient value) & 0.3 & 0.2 & 0.4 & $<0.01$ \\
\hline
\end{tabular}

${ }^{1}$ Nonsteroidal anti-inflammatory drug.

${ }^{2}$ Nova Scotia, New Brunswick, Prince Edward Island, and Newfoundland and Labrador.

${ }^{3}$ British Columbia, Alberta, Saskatchewan, and Manitoba.

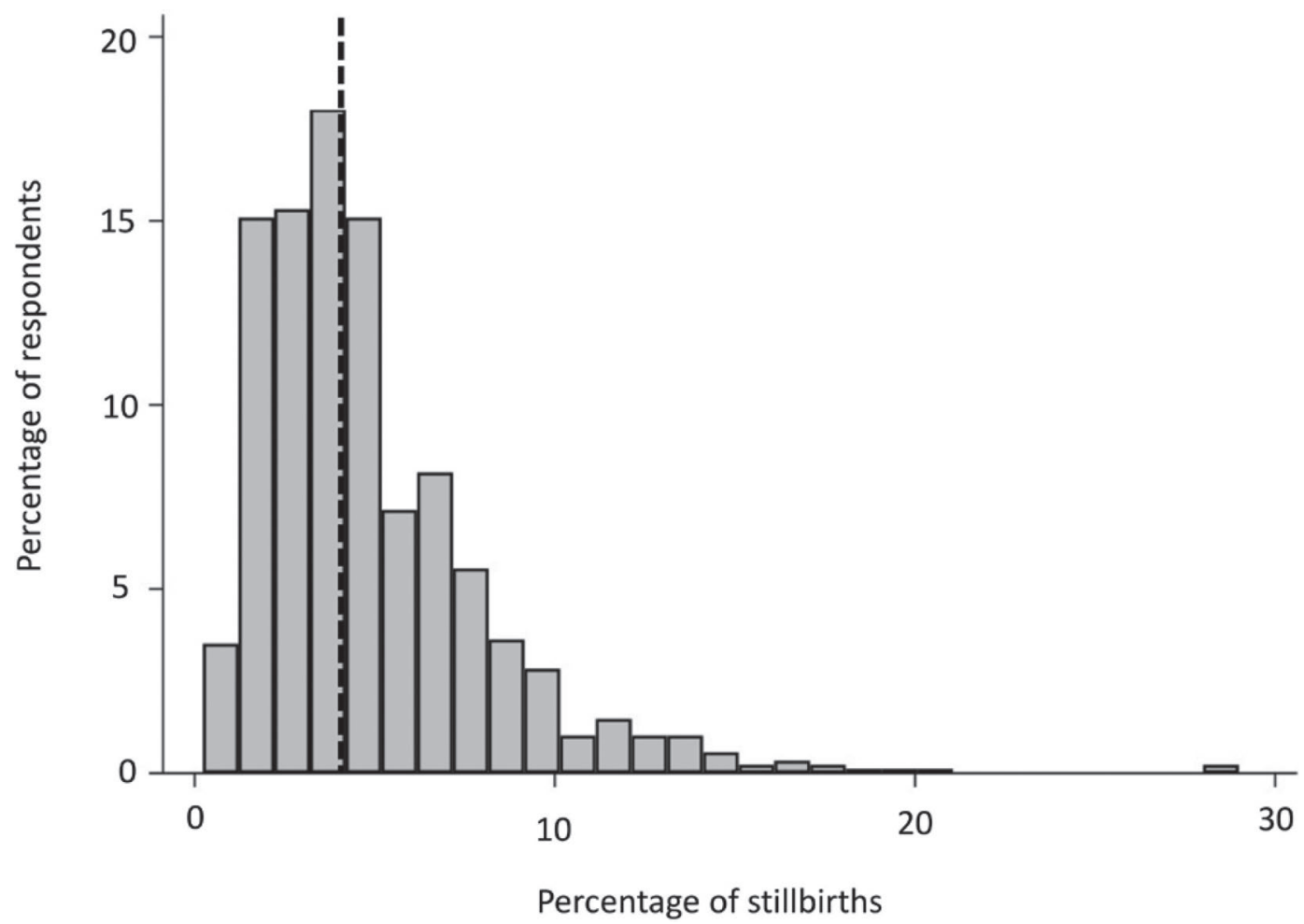

Figure 4. Distribution of stillbirths (calves born dead or died within the first $48 \mathrm{~h}$ ) by percentage of Canadian dairy producer respondents $(\mathrm{n}=889)$. The vertical dashed line reflects the median reported value of $4.1 \%$. 


\section{DISCUSSION}

\section{Study Population and Response Rate}

Size of farms in the respondent population generally reflected the source. Respondents had a mean of 77 milking cows compared with 86 total cows (milking and dry) as reported by Statistics Canada/Canadaina Dairy Information Center (CDIC, 2017). The proportion of AMS milking systems in our survey was $11 \%$, compared with 10\% (CDIC, 2017). Although our proportion of tiestall herds $(60 \%)$ was lower than reported by the CDIC (74\%), the latter includes only herds enrolled in milk recording, whereas in our data set, all dairy farms in Canada were eligible, and we found the tiestall proportion to be larger in our respondents enrolled in milk recording compared with those not enrolled.

Our survey response rate was higher than that of other recent national surveys of Canadian dairy producers (6\%, Medrano-Galarza et al., 2017; 7\%, DenisRobichaud et al., 2018). Given the length of our survey, and the fact that we had only one opportunity to contact respondents, the response rate of $12 \%$ exceeded expectations.

\section{Calf Health and Management Practices}

Appropriate feeding of colostrum is an important factor accounting for a substantial part of mortality risk in the first $3 \mathrm{wk}$ of life (Wells et al., 1996) as well as in the postweaning period (Tyler et al., 1998). In total, $14 \%$ of respondents allowed calves to suckle their dam always or most of the time; this practice has changed substantially over time, as natural suckling of colostrum was reported to be the main source of colostrum by $43 \%$ of Ontario producers in a 1980 survey (Waltner-Toews et al., 1986). Whereas over half of our respondents reported never allowing heifer calves to nurse their dams, less than one-quarter also reported always removing calves within 30 min of birth. This was similar to the 2015 NAHMS results in the United States, where less than one-quarter reported removing calves from the calving pen within an hour of birth (UDSA-APHIS, 2015). Longer time spent by calves in the calving pen is associated with increased odds of failure of passive transfer and agammaglobulinemia (Vogels et al., 2013). In our study, the discrepancy between stating that calves are never allowed to nurse the dam and not always removing calves from the calving pen within 30 min may indicate that the former response may not accurately reflect onfarm practices, or could indicate that other methods are used by the producer to prevent nursing, such as partially segregating calves in a container within the calving pen. Some producers may assume that calves are not able to stand and nurse between birth and the time the producer removes them from the calving pen, even if this is longer than $30 \mathrm{~min}$. Factors associated with adoption of both practices were similar, such as always cleaning calving pens between use. In many of our analyses, adoption of best practices around calving and neonatal care were often associated; reporting the removal of calves within $30 \mathrm{~min}$ of birth was positively associated with both evening/overnight colostrum feeding and volume fed in the preweaning period, whereas never allowing calves to nurse their dam was associated with the use of separate calving pens from sick pens, feeding heat-treated colostrum, and cleanliness of cows before calving. Similar positive associations with other colostrum management practices were present for producers who always fed $4 \mathrm{~L}$ of colostrum within the first $12 \mathrm{~h}$ for heifer calves, although also positively associated in this analysis was being aware of the Code of Practice for the Care and Handling of Dairy Cattle (National Farm Animal Care Council, 2009).

Regular overnight colostrum feeding was uncommon, even among large farms. Vasseur et al. (2010) previously reported that surveillance of the calving pen between 1800 and $0600 \mathrm{~h}$ is infrequent, which would, at best, also reflect potential colostrum feedings. Although evening or overnight feeding of colostrum in our survey was positively associated with other colostrum feeding practices, it was less likely to occur on farms where preweaned calves were housed in groups. This may reflect a desire to reduce labor: overnight observation and colostrum feeding may be less frequent in operations where labor is in short supply. The effect of overnight feedings was not associated with herd size, which was unexpected because we would expect larger farms to be more likely to have staff present at extended hours. Instead, specific management philosophies might differ between farms both choosing to house calves in groups and feed colostrum overnight, as opposed to only being an economy of scale. This is somewhat in contrast with findings in the United States, where the amount of colostrum fed in the first $24 \mathrm{~h}$ increased with herd size (USDA-APHIS, 2015). Maximum herd size is much larger in the United States than in Canada, and perhaps the effect of size on likelihood of overnight feedings is more pronounced in very large (e.g., $>1,000$ cow) farms.

Early life nutrition affects calf survival (Godden et al., 2005), and preweaning nutritional stress affects cortisol levels (Roland et al., 2016) and calf behavior (Rosenberger et al., 2017); milk allowance directly affects health and welfare. Although mean maximum milk fed was $8.2 \mathrm{~L} / \mathrm{d}$, one-third of producers fed $\leq 6$ $\mathrm{L} / \mathrm{d}$, which has been shown to cause signs of chronic hunger (Rosenberger et al., 2017). In winter, $6 \mathrm{~L}$ of 
milk per day may not be adequate to maintain "health, growth, and vigor" as required by the Code of Practice, and does not meet the Code's recommendation of feeding 20\% of BW for average Holstein calves (National Farm Animal Care Council, 2009). In our study, higher maximum milk allowance was associated with group housing, which may reflect use of an automated feeder. Higher allowance was associated with 2 best management practices: always cleaning calving pens between uses and disbudding calves before 8 wk of age. This, coupled with the effect of age, might indicate individuals who may be more likely to track and implement newer technologies or ideas. Medrano-Galarza et al. (2017) also reported that younger producers were more likely to have an automated milk feeder, which was in turn associated with increased plane of nutrition. The reported volume of milk fed in this study appears to be higher than that in the United States, where half of all operations fed $\leq 5 \mathrm{~L} / \mathrm{d}$ (UDSA-APHIS, 2015), although this is somewhat difficult to compare, as our survey asked for maximum volume fed per day, which may not reflect typical daily averages. That said, it is unlikely that farms reporting feeding large volumes at maximum milk allowance would have extended periods where calves are fed low volumes of milk.

Overall, best management practices to avoid disease and improve health in early life were often associated with one another in many of the analyses. For example, best practices such as avoiding disbudding at older ages, where evidence indicates the procedure of surgical amputation is more painful than cautery (Petrie et al., 1996), was associated with increased plane of nutrition in early life. Producers who report adoption of one best management practice may be generally likely to adopt others with regard to preweaned calves. Adoption of new strategies depends on a multitude of factors, including personal characteristics and their perceived ability to make changes (Ritter et al., 2017). Although changing disbudding practices has a different set of costs and benefits compared with increasing preweaned calves' nutritional plane, a producer who is perceptive of one opportunity and feels motivated to make changes may be more likely to similarly view an opportunity in another area that affects calf health and welfare. Although there were some associations with respondent age, 305-d mature-equivalent milk yield, number of milking cows, and barn type in individual analyses, these were not seen consistently among the newborn calf management practices examined. These farm and individual characteristics may account for some of the differences in adoption of management practices between respondents, but this information probably does not entirely capture all differences between adopters and nonadopters, which may stem from differences in attitudes, goals, and philosophy not being reflected in traditionally captured demographic information.

\section{Disbudding and Dehorning Practices}

Use of local anesthetics, NSAID analgesics, and sedatives commonly associated with one another, which was expected. However, it is important to note that neither those reporting use of NSAID nor local anesthesia are a perfect subset (i.e., some respondents used one medication but not the other). Some producers may use one medication without the other, perhaps as a result of believing the second medication is not needed. For example, the association of cautery disbudding at a young age with decreased odds of use of an NSAID may reflect an incorrect assumption that younger animals do not benefit from analgesia. In many countries, recommendations on pain control are based on calf age, with analgesia only required after a specific age (European Commission, 1988; New Zealand National Animal Welfare Advisory Committee, 2005). Age cutpoints suggest that young animals do not benefit from pain control for disbudding; however, this has not been reported in the peer-reviewed literature. Previous reported use of NSAIDs among producers has been very low (Hoe and Ruegg, 2006; Fulwider et al., 2008; Vasseur et al., 2010), and is also low among veterinarians performing this practice (Huxley and Whay, 2006; Hewson et al., 2007; Misch et al., 2007; Fajt et al., 2011). However, recent evidence indicates this is now increasing in use among both veterinarians and dairy producers, and the use of sedation, local anesthetic, and NSAID in this survey was very similar to that reported in 2014 in Ontario (Winder et al., 2016). The Ontariobased survey was primarily focused on disbudding and dehorning practices; the title of the survey was clear in this aspect, and there may have been a differential nonresponse bias from those producers not using pain control. In the national survey, it is less likely that the same differential nonresponse bias would occur based on the stated goals and breadth of the national survey, which were not focused specifically on pain control for disbudding. Over $95 \%$ of respondents to the national survey answered the disbudding section, including pain control use. As the proportion of respondents using each medication type was very similar between the 2 surveys, this likely reflects actual medication use on Canadian farms. Although this evidence of substantial improvement in the adoption of local anesthetic and NSAID analgesia for disbudding is encouraging, there is room for substantial improvement to meet the industry requirement (Dairy Farmers of Canada, 2015) of all 
producers using appropriate pain mitigation for these practices.

We found a positive association between use of both social media and high-speed internet and use of local anesthesia for cautery disbudding. Interestingly, age and education level were not significant in any of the 3 medication use models, and were not associated with social media or high-speed internet use. Somewhat similarly, use of sedation in the Ontario-based survey was associated with use of Twitter for professional purposes (Winder et al., 2016). This supports the idea that connection to information through online access may be a more useful predictor of awareness of recommended management procedures and willingness to improve on farm practices compared with traditional demographic descriptors such as age and education.

\section{Stillbirths and Heifer Mortality}

Stillbirth rate and calf mortality in this survey were similar to that reported in a survey of intensive dairy farms in Italy (Zucali et al., 2013), and higher than that in a survey of pasture-based farms in New Zealand (Cuttance et al., 2017). Calf mortality rates vary substantially among studies, as shown by significant heterogeneity (Cochrane's $Q$ test) in a systematic review and meta-analysis conducted by Compton et al. (2017). This heterogeneity may reflect, in part, regional differences between industries; for example, seasonal calving may allow for a more intensive focus on calf care compared with year-round calving, and fluctuations in calf numbers in a year-round system may stress housing allowances more substantially than in a seasonal-based industry.

Odds of above-average stillbirth rate decreased with increasing herd size and with being a DHI participant. This may be a result of more accurate data from those in milk recording; however, the effect of herd size is independent of this factor. A protective effect of herd size was also seen in the NAHMS 2015 Dairy Study (UDSAAPHIS, 2015). Although it is possible that large herds have more accurate records, our findings are in contrast to surveys done in Mexico (Mellado et al., 2014) and northern Europe (Gulliksen et al., 2009; Seppä-Lassila et al., 2016), where increasing herd size was associated with increased mortality risk. Average herd size in Norway and Finland is substantially smaller than that in Canada (Barkema et al., 2015), and the study in northern Mexico found that dairies with $>1,800$ cows had a higher risk of calf mortality than those with fewer cows; differences in management and risk factors between $\mathrm{Ca}$ nadian farms and these studies may explain the different direction of association with herd size in our study.
Larger farms in our study might have been more likely to have protocols in place for calf management and might more often have a dedicated staff member focused on calf health. Similarly, these factors could hold true for the association between herd size and preweaning mortality. An increasing percentage of stillbirths and postweaning mortality were positively associated with increased odds of above-average preweaning mortality. Likely, management factors that contribute to poor postnatal care drive all of these similar parameters; however, no management practices identified in this survey were associated with preweaning calf mortality. This said, a substantial number of respondents (46\%) failed to provide usable data to explore calf mortality. A large number of producers did not provide responses for these questions, which differed considerably from the response rate for all other sections of the survey. This may reflect a lack of these data being captured on farm or may represent a reluctance by producers to discuss this topic. Interestingly, the questions regarding pain control for dehorning - another socially contentious issue in the dairy industry - had a much higher response rate than the mortality questions, which may suggest that a lack of primary data capture on farm is primarily responsible for this incongruity. Age of identification by Québec dairy producers ranged from birth to $45 \mathrm{~d}$ (mean of $3 \mathrm{~d}$; Vasseur et al., 2010), which may also indicate a lack of early mortality event recording. Mandatory reporting of calf birth and death loss events will become mandatory in Canada as part of the traceability component of the proAction program (Dairy Farmers of Canada, 2015). This could allow for analysis of database recordings similar to that done by Gulliksen et al. (2009) using information from the Norwegian Dairy Herd Recording System, which has similar reporting requirements.

\section{Limitations}

A concern with any survey is that answers may not necessarily reflect true practices on the farm; however, differences in responses at minimum indicate disparities among producers in knowledge, and perhaps availability of knowledge translation efforts in their community. Selection of best management practices as the "correct" response may, at minimum, indicate intent. A lower response rate to mortality questions, coupled with a large number of reported zero values, left a smaller proportion of respondents from which to model factors associated with calf mortality. As a result, it may be less likely the results from these analyses reflect the population compared with sections with a more robust response rate. 


\section{CONCLUSIONS}

This survey provides useful benchmarking information on the care and management of heifer calves on Canadian dairy farms. Although the large majority of producers report that they always perform some colostrum best management practices, such as always feeding $4 \mathrm{~L}$ within the first $12 \mathrm{~h}$ after birth, subsequent questions on the daily management of the farm, such as overnight feeding, may identify inconsistency between reported practices and actual occurrences on farm. Best predictors of best management practices for the care of pre- and postpartum cows and neonatal calves were often associated with each other but were not routinely associated with other demographic factors examined in this survey. As in the United States, stillbirth rate was associated with herd size, whereas preweaning calf mortality was associated with herd size, stillbirth rate, and postweaning mortality events. A distinct lack of information provided in the mortality section of this survey was unlike all other sections; this study therefore identifies an important factor toward improving calf health in the industry. Ensuring calf mortality data are routinely collected on farm will serve to provide information not only to producer and advisors on a farm-level basis, but also to industry with a more comprehensive understanding of calf health on Canadian dairy farms. Without this information, it is far more challenging to identify the key obstacles facing optimal heifer calf health and productivity.

\section{ACKNOWLEDGMENTS}

The authors thank all respondents to the $2015 \mathrm{Na}$ tional Dairy Study, which was funded by Dairy Farmers of Canada (Ottawa, ON, Canada) and Agriculture and Agri-Food Canada (Ottawa, ON, Canada) through the Dairy Research Cluster 2 Program. The first author was funded by the Ontario Ministry of Agriculture, Food and Rural Affairs (Guelph, ON, Canada), and through the Ontario Graduate Scholarship Program (University of Guelph).

\section{REFERENCES}

Barkema, H. W., M. A. G. von Keyserlingk, J. P. Kastelic, T. J. G. M. Lam, C. Luby, J.-P. Roy, S. J. LeBlanc, G. P. Keefe, and D. F. Kelton. 2015. Invited review: Changes in the dairy industry affecting dairy cattle health and welfare. J. Dairy Sci. 98:7426-7445.

Bauman, C. A., H. W. Barkema, J. Dubuc, G. P. Keefe, and D. F Kelton. 2016. Identifying management and disease priorities of Canadian dairy industry stakeholders. J. Dairy Sci. 99:10194-10203.

Bauman, C. A., H. W. Barkema, J. Dubuc, G. P. Keefe, and D. F. Kelton. 2018. Canadian National Dairy Study: Herd-level milk quality. J. Dairy Sci. 101:2679-2691.

Belage, E., S. Dufour, C. Bauman, A. Jones-Bitton, and D. F. Kelton. 2017. The Canadian National Dairy Study 2015-Adoption of milking practices in Canadian dairy herds. J. Dairy Sci. 100:3839 3849 .

Canadian Dairy Commission. 2015. The industry: Production: Number of Farms by Province. Accessed Mar. 30, 2018. www.cdc-ccl .gc.ca.

Canadian Dairy Information Center. 2017. Dairy facts and figures. Accessed Mar. 30, 2018. http://www.dairyinfo.gc.ca/index_e.php ?s1=dff-fcil\#farm

Compton, C. W. R., C. Heuer, P. T. Thomsen, T. E. Carpenter, C. V. C. Phyn, and S. McDougall. 2017. Invited review: A systematic literature review and meta-analysis of mortality and culling in dairy cattle. J. Dairy Sci. 100:1-16.

Cuttance, E. L., W. A. Mason, J. McDermott, R. A. Laven, S. McDougall, and C. V. C. Phyn. 2017. Calf and replacement heifer mortality from birth until weaning in pasture-based dairy herds in New Zealand. J. Dairy Sci. 100:8347-8357.

Dairy Farmers of Canada. 2015. proAction: Leading the way for sustainable dairy farming; providing assurance to customers about farm practices. Dairy Farmers of Canada, Ottawa, ON, Canada. Accessed Feb. 9, 2018. https://www.dairyfarmers.ca/Media/Files/ proaction/proaction_ang_lr15.pdf.

Denis-Robichaud, J., R. L. A. Cerri, A. Jones-Bitton, and S. J. LeBlanc. 2018. Dairy producers' attitudes towards reproductive management and performance on Canadian dairy farms. J. Dairy Sci 101:850-860.

European Commission. 1988. The European Convention of 1976 for the Protection of Animals kept for Farming Purposes: Recommendation Concerning Cattle (Article 17). Accessed Feb. 9, 2018. http://www.coe.int/t/e/legal_affairs/legal_cooperation/biological _safety_and_use_of_animals/farming/Rec\%20cattle\%20E.asp.

Fajt, V. R., S. A. Wagner, and B. Norby. 2011. Analgesic drug administration and attitudes about analgesia in cattle among bovine practitioners in the United States. J. Am. Vet. Med. Assoc. 238:755-767.

Fulwider, W. K., T. Grandin, B. E. Rollin, T. E. Engle, N. L. Dalsted, and W. D. Lamm. 2008. Survey of dairy management practices on one hundred thirteen north central and northeastern United States dairies. J. Dairy Sci. 91:1686-1692.

Gelsinger, S. L., C. M. Jones, and A. J. Henrichs. 2015. Effect of colostrum heat treatment and bacterial population on immunoglobulin G absorption and health of neonatal calves. J. Dairy Sci. 98:4640-4645.

Godden, S. M., J. P. Fetrow, J. M. Feirtag, L. R. Green, and S. J. Wells. 2005. Economic analysis of feeding pasteurized nonsaleable milk versus conventional milk replacer to dairy calves. J. Am. Vet. Med. Assoc. 226:1547-1554.

Gulliksen, S. M., K. I. Lie, T. Løken, and O. Østerås. 2009. Calf mortality in Norwegian dairy herds. J. Dairy Sci. 92:2782-2795.

Hewson, C. J., I. R. Dohoo, K. A. Lemke, and H. W. Barkema. 2007. Canadian veterinarians' use of analgesics in cattle, pigs, and horses in 2004 and 2005. Can. Vet. J. 48:155-164.

Hoe, F. G., and P. L. Ruegg. 2006. Opinions and practices of Wisconsin dairy producers about biosecurity and animal well-being. J. Dairy Sci. 89:2297-2308.

Huxley, J. N., and H. R. Whay. 2006. Current attitudes of cattle practitioners to pain and the use of analgesics in cattle. Vet. Rec. 159:662-668.

Kertz, A. F., T. M. Hill, J. D. Quigley III, A. J. Heinrichs, J. G. Linn, and J. K. Drackley. 2017. A 100-year review: Calf nutrition and management. J. Dairy Sci. 100:10151-10172.

Medrano-Galarza, C., S. J. LeBlanc, T. J. DeVries, A. Jones-Bitton, J. Rushen, A. M. de Passillé, and D. B. Haley. 2017. A survey of dairy calf management practices among farms using manual and automated milk feeding systems in Canada. J. Dairy Sci. 100:6872-6884.

Mellado, M., E. Lopez, F. G. Veliz, M. A. De Santiago, U. MaciasCruz, L. Avendaño-Reyes, and J. E. Garcia. 2014. Factors associated with neonatal dairy calf mortality in a hot-arid environment. Livest. Sci. 159:149-155.

Misch, L. J., T. F. Duffield, S. T. Millman, and K. D. Lissemore. 2007. An investigation into the practices of dairy producers and 
veterinarians in dehorning dairy calves in Ontario. Can. Vet. J. 48:1249-1254.

New Zealand National Animal Welfare Advisory Committee. 2005. Animal Welfare (Painful Husbandry Practices) Code of Welfare 2005. Accessed Feb. 9, 2018. http://www.mpi.govt.nz/dmsdocument/ $1443 /$.

NFACC (National Farm Animal Care Council). 2009. Code of practice for the care and handling of dairy cattle. National Farm Animal Care Council, Lacombe, AB, Canada. Accessed Feb. 9, 2018. http: //www.nfacc.ca/codes-of-practice/dairy-cattle.

Petrie, N. J., D. J. Mellor, K. J. Stafford, R. A. Bruce, and R. N. Ward. 1996. Cortisol responses of calves to two methods of disbudding used with or without local anesthetic. N. Z. Vet. J. 44:9-14.

Raboisson, D., F. Delor, E. Cahuzac, C. Gendre, P. Sans, and G. Allaire. 2013. Perinatal, neonatal, and rearing period mortality of dairy calves and replacement heifers in France. J. Dairy Sci. 96:2913-2924.

Ritter, C., J. Jansen, S. Roche, D. F. Kelton, C. L. Adams, K. Orsel, R. J. Erksine, G. Benedictus, T. J. G. M. Lam, and H. W. Barkema. 2017. Invited review: Determinants of farmers' adoption of management-based strategies for infectious disease control and prevention. J. Dairy Sci. 100:3329-3347.

Roland, L., M. Drillich, D. Klein-Jöbstl, and M. Iwersen. 2016. Invited review: Influence of climatic conditions on the development, performance, and health of calves. J. Dairy Sci. 99:2438-2452.

Rosenberger, K., J. H. C. Costa, H. W. Neave, M. A. G. von Keyserlingk, and D. M. Weary. 2017. The effect of milk allowance on behavior and weight gains in dairy calves. J. Dairy Sci. 100:504-512.

Seppä-Lassila, L., K. Sarjokari, M. Hovinen, T. Soveri, and M. Norring. 2016. Management factors associated with mortality of dairy calves in Finland: A cross-sectional study. Vet. J. 216:164-167.

Soberon, F., and M. E. Van Amburgh. 2013. Lactation Biology Symposium: The effect of nutrient intake from milk or milk replacer of preweaned dairy calves on lactation milk yield as adults: A metaanalysis of current data. J. Anim. Sci. 91:706-712.

Sumner, C. L., M. A. G. von Keyserlingk, and D. M. Weary. 2018. How benchmarking motivates farmers to improve dairy calf management. J. Dairy Sci. 101:3323-3333.
Trotz-Williams, L. A., K. E. Leslie, and A. S. Peregrine. 2008. Passive immunity in Ontario dairy calves and investigation of its association with calf management practices. J. Dairy Sci. 91:3840-3849.

Tyler, J. W., D. D. Hancock, S. E. Wiksie, S. L. Holler, J. M. Gay, and C. C. Gay. 1998. Use of total protein as a predictor of calf mortality. J. Vet. Intern. Med. 12:79-83.

USDA-APHIS. 2015. Dairy 2014: Dairy cattle management practices in the United States, 2014. USDA Animal and Plant Health Inspection Service. Accessed Feb. 9, 2018. https://aphis.usda.gov/ animal_health/nahms/dairy/downloads/dairy14/Dairy14_dr PartI.pdf.

USDA-APHIS. 2016. About NAHMS. USDA Animal and Plant Health Inspection Service. Accessed Feb. 9, 2018. https://aphis.usda.gov/ aphis/ourfocus/animalhealth/monitoringand-surveillance/nahms/ about.

Vasseur, E., F. Borderas, R. I. Cue, D. Lefebvre, D. Pellerin, J. Rushen, K. M. Wade, and A. M. de Passillé. 2010. A survey of dairy calf management practices in Canada that reflect animal welfare. J. Dairy Sci. 93:1307-1315.

Vogels, Z. G. M. Chuck, and J. M. Morton. 2013. Failure of transfer of passive immunity and agammaglobulinaemia in calves in southwest Victorian dairy herds: Prevalence and risk factors. Aust. Vet. J. 91:150-158.

von Keyserlingk, M. A., and D. M. Weary. 2017. A 100-Year Review: Animal welfare in the Journal of Dairy Science-The first 100 years. J. Dairy Sci. 100:10432-10444.

Waltner-Toews, D., S. W. Martin, A. H. Meek, and I. McMillan. 1986. Dairy calf management, morbidity, and mortality in Ontario Holstein herds. I. The data. Prev. Vet. Med. 4:103-124.

Wells, S., D. A. Dargatz, and S. L. Ott. 1996. Factors associated with mortality to 21 days of life. Prev. Vet. Med. 29:9-19.

Winder, C. B., S. J. LeBlanc, D. B. Haley, K. D. Lissemore, M. A Godkin, and T. F. Duffield. 2016. Practices for the disbudding and dehorning of dairy calves by veterinarians and dairy producers in Ontario, Canada. J. Dairy Sci. 99:10161-10173.

Zucali, M., L. Bava, A. Tamburini, M. Guerci, and A. Sandrucci. 2013. Management risk factors for calf mortality in intensive Italian dairy farms. Ital. J. Anim. Sci. 12:162-166. 